\title{
EKTRAKSI SILIKON DIOKSIDA DARI DAUN BAMBU
}

\author{
Hallimah Sa'diyah ${ }^{1, *}$, Salamet Nurhimawan ${ }^{1}$, Sigit Ahmad Fatoni ${ }^{1}$, Irmansyah $^{2}$, Irzaman ${ }^{2}$ \\ ${ }^{1}$ Mahasiswa S1 Departemen Fisika, FMIPA, Institut Pertanian Bogor, \\ Jalan Meranti Gedung Wing S no 3 Dramaga Bogor - 16680 \\ 2 Staf Pengajar Departemen Fisika, FMIPA, Institut Pertanian Bogor, \\ Jalan Meranti Gedung Wing S no 3 Dramaga Bogor - 16680 \\ ${ }^{*}$ Email: diyah4919@gmail.com
}

\begin{abstract}
Abstrak
Telah diperoleh ekstrak silika dari daun bambu dengan pencucian $\mathrm{HCl} 7 \%$ p.a. Setelah daun bambu dibakar, arang daun bambu dipanaskan dalam tanur yang masih bersuhu kamar. Dengan laju annealing 0.9 dan $1{ }^{\circ} \mathrm{C} /$ menit, suhu dinaikkan hingga $400{ }^{\circ} \mathrm{C}$ dengan waktu penahanan 2 jam kemudian suhu dinaikkan kembali hingga $950{ }^{\circ} \mathrm{C}$ dengan waktu penahanan 1 jam. Abu kemudian dicuci dengan $\mathrm{HCl}$ dan dibilas dengan aquabides hingga nilai $\mathrm{pH}$ netral. Selanjutnya abu dikeringkan dalam tanur dengan suhu $1000{ }^{\circ} \mathrm{C}$. Hasil analisis EDX menunjukkan kemurnian sampel silika sebesar 84.53\% sampai 99.99\%. Sedangkan analisis FTIR menunjukkan sampel silika memiliki pita serapan pada bilangan gelombang $1071 \mathrm{~cm}^{-1}, 1060$ $\mathrm{cm}^{-1}$ dan $798 \mathrm{~cm}^{-1}$ yang menunjukkan adanya vibrasi ulur asimetri $\mathrm{Si}-\mathrm{O}$ dari gugus siloksan ( $\mathrm{Si}-\mathrm{O}-\mathrm{Si}$ ).
\end{abstract}

Kata Kunci: silika, daun bambu, tingkat kemurnian, gugus fungsi.

\begin{abstract}
Silika extract has got from bamboo leaf by leaching with $\mathrm{HCl} 7 \%$ p.a. After bamboo leaf was burned, the charcoal was heated in the furnace with annealing rates of 0.9 and $1{ }^{\circ} \mathrm{C} /$ minute. The first temperature was room temperature, then increased to $400{ }^{\circ} \mathrm{C}$ with 2 hours arrested time. And last increased to $950{ }^{\circ} \mathrm{C}$ with 1 hour arrested time. The resulting ash was leached with $\mathrm{HCl} 7 \%$ p.a and its $\mathrm{pH}$ was neutralisted by aquabides. Then, the neutral ash was heated in furnace at $1000{ }^{\circ} \mathrm{C}$. The result of $\mathrm{EDX}$ analysis showed that silica samples have purity levels of $84.53 \%$ to $99.99 \%$. FTIR result showed that silica samples have absorption bands at wave numbers of $1071 \mathrm{~cm}^{-1}, 1060 \mathrm{~cm}^{-1}$ and $\quad 798 \mathrm{~cm}^{-1}$ which indicate the
\end{abstract} asymetric stretching vibration of $\mathrm{Si}-\mathrm{O}$ from siloxane group.

Keywords: silica, bamboo leaves, purity level, function group.

\section{Pendahuluan}

Bambu merupakan salah satu jenis rumput rumputan yang termasuk ke dalam family Graminae. Tanaman bambu banayak tersebar di negara tropis dan dapat tumbuh di dataran rendah hingga lereng pegunungan. Bambu merupakan hasil hutan non kayu yang umumnya digunakan sebagai bahan konstruksi rumah seperti dinding, tiang dan atap [1]. Tanaman bambu juga banyak digunakan sebagai produk industri seperti furniture, bahan campuran kaca dan keramik serta bahan mentah industri Pulp \& Paper [2]. Indonesia memiliki 143 jenis pohon bambu termasuk yang tumbuh liar dan belum termanfaatkan. Tanaman bambu memiliki penyebaran yang lebih banyak di pulau Jawa yaitu mencapai 29.14 juta rumpun $(76.83 \%)$ dari total populasi bambu di Indonesia [3]. Apabila bambu dimanfaatkan, bagian yang banyak digunakan adalah bagian batang. Sedangkan daun yang dihasilkan hanya dibiarkan menjadi limbah agro. Padahal, kandungan silika yang cukup tinggi di abu daun bambu, menjadikan daun bambu berpotensi sebagai penghasil silika. Silika yang berasal dari bahan organik dikenal dengan nama bio-silika [4]. Bahan organik yang biasanya digunakan sebagai penghasil bio-silika adalah 
sekam padi karena sekam padi merupakan bahan organik yang paling banyak mengandung silika [5]. Namun Indonesia hanya memiliki dua kali masa tanam padi ditambah dengan banyaknya pengurangan lahan pertanian menjadikan sekam padi masih terbatas bila dibandingkan dengan daun bambu yang jumlahnya melimpah dan belum termanfaatkan.

Kandungan abu daun bambu atau bamboo leaf ash (BLA) dari daun bambu sebesar 20\% dengan kandungan silika sebesar 75.90 - $82.86 \%$, di mana kandungan silika abu daun bambu ini merupakan yang terbesar kedua setelah abu sekam padi yaitu sebesar 93.2\% [6]. Akan tetapi, persentase impuritas pada abu daun bambu (senyawa selain $\mathrm{SiO}_{2}$ ) cukup tinggi bila dibandingkan dengan impuritas pada abu sekam padi.

Tabel 1. Perbandingan persentase senyawa antara abu sekam padi dan daun bambu [6].

\begin{tabular}{lllllllll}
\hline Material & $\begin{array}{l}\mathrm{SiO}_{2} \\
(\%)\end{array}$ & $\begin{array}{l}\mathrm{Al}_{2} \mathrm{O}_{3} \\
(\%)\end{array}$ & $\begin{array}{l}\mathrm{Fe}_{2} \mathrm{O}_{3} \\
(\%)\end{array}$ & $\begin{array}{l}\mathrm{CaO} \\
(\%)\end{array}$ & $\begin{array}{l}\mathrm{MgO} \\
(\%)\end{array}$ & $\begin{array}{l}\mathrm{Na}_{2} \mathrm{O} \\
(\%)\end{array}$ & $\begin{array}{l}\mathrm{K}_{2} \mathrm{O} \\
(\%)\end{array}$ & $\begin{array}{l}\text { Lain- } \\
\text { lain (\%) }\end{array}$ \\
\hline $\begin{array}{l}\text { Abu Sekam } \\
\text { padi }\end{array}$ & 93.2 & 0.4 & 0.1 & 1.1 & 0.1 & 0.1 & 1.3 & 3.7 \\
\hline $\begin{array}{l}\text { Abu Daun } \\
\text { bambu }\end{array}$ & 75.90 & 4.13 & 1.22 & 7.47 & 1.85 & 0.21 & 5.2 & 4.02 \\
\hline
\end{tabular}

Senyawa kimia silikon dioksida (silika) memiliki rumus kimia $\mathrm{SiO}_{2}$. Atom silikon dapat membentuk empat ikatan secara serentak yang tersusun secara tetrahedral. Dalam silika, setiap atom Si terikat pada empat atom $\mathrm{O}$ dan setiap atom $\mathrm{O}$ terikat pada dua sisi atom Si. Penyusunan struktur tersebut meluas menjadi jaringan yang sangat besar [7].

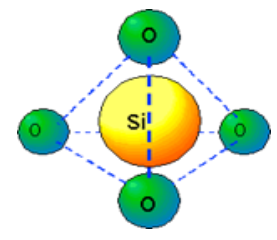

Gambar 1. Struktur kristal Silika [8].

Silika secara alami terdapat pada pasir kuarsa, batuan opal, batu api dan batuan permata. Silika memiliki titik didih dan titik lebur berturut-turut sebesar $3265{ }^{\circ} \mathrm{C}$ dan $1414{ }^{\circ} \mathrm{C}$ serta massa jenis sebesar 2.33 $\mathrm{gcm}^{-3}$. Senyawa ini terdapat dalam bentuk amorf (tak beraturan) atau polimerfisme kristal (bentuk kristal yg berbeda-beda) Silika merupakan kristal jernih tidak berwarna, tidak larut dalam air dan berbagai asam kecuali asam flourida (HF) [9].

Silika memiliki perananan yang cukup penting dalam dunia indutri. Silika banyak digunakan sebagai bahan pembuatan kaca, keramik, silica gel, dan asam silikat merupakan bahan mentah untuk produksi soluble silicate dan silicon carbide [10,11]. Namun harga silika mineral cukup mahal dan penggunaan silika dari bahan organik sudah mulai diwacanakan sebagai sumber alternatif silikon dalam penindustrian chip silicon [12].
Tahun 2015, Aminullah mengekstrak silika dari daun bambu dengan pencucian $\mathrm{HCl} 3 \%$ teknis. Berdasarkan uji EDX diperoleh kemurnian silika sebesar $65.85 \%$ - $74.49 \%$ dengan masih terdapat impuritas berupa $\mathrm{Al}_{2} \mathrm{O}_{3}, \mathrm{Rb}_{2} \mathrm{O}$ dan $\mathrm{Fe}_{2} \mathrm{O}_{3}$ [13]. Hal ini dimungkinkan karena $\mathrm{HCl}$ teknis masih memiliki konsentrasi rendah dan terdapat impuritas dalam $\mathrm{HCl}$ itu sendiri. Sehingga perlu adanya peralihan dari $\mathrm{HCl}$ teknis menjadi $\mathrm{HCl}$ p.a serta adanya peningkatan konsentrasi $\mathrm{HCl}$.

\section{Metode Penelitian}

Penelitian ini terdiri dari empat tahap. Tahap pertama yaitu pembakaran daun bambu. Tahap kedua adalah pengabuan arang daun bambu. Tahap ketiga adalah ekstraksi silika dan tahap keempat uji analisis komposisi logam dan gugus fungsi.

\section{Pembakaran Daun Bambu}

Daun bambu dikeringkan dengan bantuan sinar matahari lalu ditimbang sebanyak 2000 gram $(2 \mathrm{~kg}$ ). Selanjutnya daun bambu kering dibakar di ruangan terbuka tanpa tambahan bahan bakar. Arang daun bambu yang dihasilkan kemudian ditimbang dengan neraca analitik.

\section{Pengabuan Arang Daun Bambu}

Proses pengabuan dilakukan dengan mengadopsi pada beberapa penelitian mengenai proses pengabuan sekam padi [14 - 17]. Arang daun bambu ditimbang sebanyak 10 gram, kemudian dimasukkan dalam cawan porselin dan diatur sehingga memiliki ketebalan yang sama serta dibakar dalam tanur dengan suhu awal berupa suhu kamar, kemudian suhu dinaikkan menjadi $400{ }^{\circ} \mathrm{C}$ dengan waktu tahan 2 jam. Pemanasan berikutnya dilanjutkan dengan suhu $950{ }^{\circ} \mathrm{C}$ dengan waktu tahan 1 jam. Selanjutnya suhu diturunkan menjadi suhu kamar, selain itu laju kenaikan suhu diatur sebesar $0.9^{\circ} \mathrm{C} /$ menit dan $1{ }^{\circ} \mathrm{C} /$ menit.

\section{Ekstraksi Silika}

Setelah proses pengabuan, abu daun bambu ditimbang dan dicuci dengan menggunakan $\mathrm{HCl} 7 \%$ p.a. Proses pencucian ini bertujuan untuk mengurangi impuritas yang ada dalam abu daun bambu selain silika. Proses pencucian dilakukan sebagai berikut: mula-mula abu dimasukkan dalam gelas piala, lalu dicampur dengan $\mathrm{HCl} 7 \%$ p.a (yaitu $12 \mathrm{~mL} \mathrm{HCl} 7 \%$ p.a untuk 1 gram abu daun bambu), kemudian dipanaskan di atas hotplate. Tombol pengatur suhu pada hotplate diatur sehingga menunjukkan skala suhu $200{ }^{\circ} \mathrm{C}$ dan diaduk dengan magnetic stirrer pada kecepatan 240 rpm selama 2 jam. Setelah itu sampel dicuci menggunakan aquabides berulang-ulang sampai bebas asam (diuji 
dengan menggunakan $\mathrm{pH}$ indikator), lalu disaring dengan kertas saring bebas abu dan diambil endapannya. Hasil penyaringan dipanaskan dalam tanur dengan suhu $1000^{\circ} \mathrm{C}$ selama 1 jam. Sampel didinginkan dalam tanur diusahakan suhunya sama dengan suhu ruangan.

\section{Hasil dan Pembahasan}

Sampel yang diperoleh ditentukan unsur - unsur yang terkandungnya dengan karakterisasi EDX. EDX yang digunakan, yaitu tipe IVO Zeiss detector Bruker $133 \mathrm{eV}$ Jerman. Hasil uji tersebut disimpulkan pada Tabel 2.

Tabel 2. Persentase atom sampel hasil uji EDX.

\begin{tabular}{|c|c|c|}
\hline \multirow{2}{*}{ Nama Unsur } & \multicolumn{2}{|c|}{ Persentase Atom } \\
\cline { 2 - 3 } & Laju Annealing $0.9^{\circ} \mathrm{C} /$ menit & Laju Annealing $1{ }^{\circ} \mathrm{C} /$ menit \\
\hline Oksigen & 59.59 & 69.83 \\
\hline Silikon & 39.17 & 28.21 \\
\hline Rubidium & 0 & 1.96 \\
\hline Kalium & 0.56 & 0 \\
\hline Magnesium & 0.53 & 0 \\
\hline Kalsium & 0.92 & 84.53 \\
\hline Kemurnian & 99.99 & 0 \\
\hline
\end{tabular}

Tingkat kemurnian silika yang diperoleh adalah 99.99\% untuk laju annealing $0.9{ }^{\circ} \mathrm{C} /$ menit dan $84.53 \%$ untuk laju annealing $1{ }^{\circ} \mathrm{C} /$ menit. Dengan laju annealing $0.9{ }^{\circ} \mathrm{C} /$ menit telah diperoleh silikon murni. Namun masih terdapat beberapa impiuritas (kalium, magnesium dan kalsium) walaupun dalam persentase yang sangat kecil. Sedangkan untuk laju annealing 1 ${ }^{\circ} \mathrm{C} /$ menit masih terdapat impiuritas rubidium dan belum terbentuk silikon murni. Masih terdapatnya beberapa impiuritas dalam sampel, diduga pencucian dengan $\mathrm{HCl} 7 \%$ masih belum optimal sehingga belum mampuh melarutkan secara sempurna impiuritasimpiuritas yang ada. Selain itu, daun bambu memiliki jumlah impiuritas yang tinggi, sekitar 10 - 12 kali impiuritas yang terkandung dalam sekam padi [6].

Selain dikarakterisasi dengan EDX, sampel juga dikarakterisasi dengan FTIR untuk mengidentifikasi gugus fungsi sampel. Setiap serapan bilangan gelombang tertentu menggambarkan adanya suatu gugus fungsi spesifik. Pola serapan infra merah silika abu daun bambu yang dihasilkan, diperlihatkan pada gambar 2 dan 3. Sampel silika dengan laju annealing $0.9^{\circ} \mathrm{C} /$ menit memiliki pita serapan pada bilangan gelombang $798.66 \mathrm{~cm}^{-1}$ dan $1060.19 \mathrm{~cm}^{-1}$ (Gambar 2). Sedangkan sampel silika dengan laju annealing 1 ${ }^{\circ} \mathrm{C} /$ menit memiliki pita serapan dengan bilangan gelombang $798.32 \mathrm{~cm}^{-1}$ dan $1071.42 \mathrm{~cm}^{-1}$ (Gambar 3).

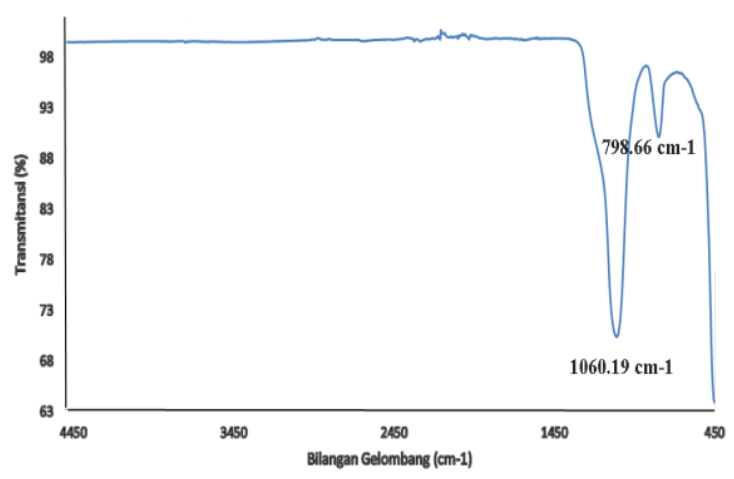

Gambar 2. Spektra FTIR sampel Silika dengan laju annealing $0.9^{\circ} \mathrm{C} / m e n i t$.

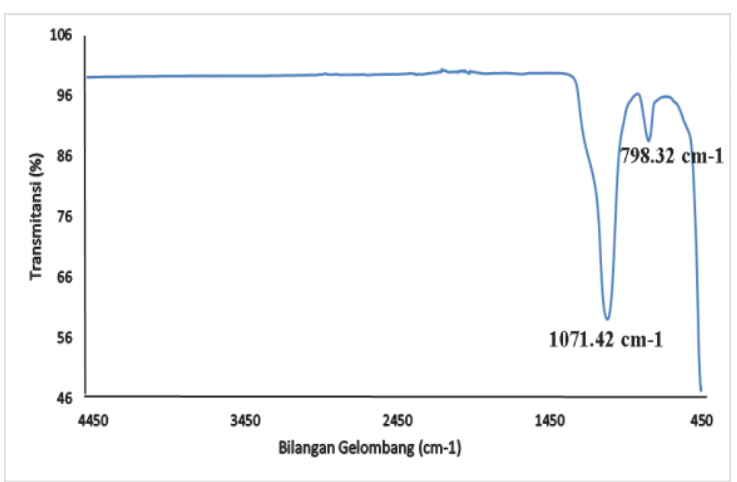

Gambar 3. Spektra FTIR sampel Silika dengan laju annealing $1^{\circ} \mathrm{C} / \mathrm{menit}$.

Pita serapan 794.6 - $806.2 \mathrm{~cm}^{-1}$ menunjukkan vibrasi ulur asimetris Si-O dari Si-O-Si [18]. Sedangkan pita serapan $1060.19 \mathrm{~cm}^{-1}$ dan 1071.42 $\mathrm{cm}^{-1}$ juga menunjukkan vibrasi ulur asimetri $\mathrm{Si}-\mathrm{O}$ dari 
Si-O-Si [19]. Selain pita serapan tersebut, masih ada pita serapan lain, yaitu $455-470 \mathrm{~cm}^{-1}$ menunjukkan vibrasi tekuk Si-O dari $\mathrm{Si}-\mathrm{O}-\mathrm{Si}$ dan pita serapan paada bilangan gelombang $620 \mathrm{~cm}^{-1}$ menunjukkan vibrasi ulur Si-O dari Si-O-Si [18]. Namun, tidak terdeteksi adanya puncak pada bilangan-bilangan gelombang tersebut. Hal ini diduga, pada bilanganbilangan gelombang tersebut tertutup gugus molekul atau gugus molekul tersebut lebih kompleks [13]. Bilangan-bilangan gelombang pada daun bambu ini mirip dengan bilangan gelombang sekam padi, yaitu $1088 \mathrm{~cm}^{-1}, 625 \mathrm{~cm}^{-1}, 471 \mathrm{~cm}^{-1}$ dan $486 \mathrm{~cm}^{-1}$ [16].

\section{Simpulan}

Hasil uji EDX menunjukkan sampel dengan laju annealing $0.9{ }^{\circ} \mathrm{C} /$ menit telah terbentuk silikon dan memiliki kemurnian $99.9 \%$. Sedangkan sampel dengan laju annealing $1{ }^{\circ} \mathrm{C} /$ menit belum terdapat silikon dan memiliki kemurnian $84.53 \%$. Namun, kedua sampel masih terdapat beberapa impiuritas, yaitu kalium, kalsium dan magnesium (laju annealing $0.9{ }^{\circ} \mathrm{C} /$ menit) serta rubidium (laju annealing 1 ${ }^{\circ} \mathrm{C} /$ menit). Sementara itu, pita serapan yang dihasilkan berada pada bilangan gelombang $798 \mathrm{~cm}^{-}$ ${ }^{1}, 1060 \mathrm{~cm}^{-1}$ dan $1071 \mathrm{~cm}^{-1}$ yang menunjukkan vibrasi ulur asimetris $\mathrm{Si}-\mathrm{O}$ dari gugus $\mathrm{Si}-\mathrm{O}-\mathrm{Si}$.

\section{Ucapan Terimakasih}

Terima kasih kepada Direktorat Penelitian dan Pengabdian Kepada Masarakat Direktorat Jenderal Pendidikan Tinggi Kementrian Pendidikan dan Kebudayaan yang telah memberikan dana hibah Program Kreativitas Mahasiswa 2015.

\section{Daftar Acuan}

[1] Latif MA, Tarmeze WAW, Fauzidah A. Anatomical freatures and mechanical properties of tree Malaysian bamboos, J Trofical Forest Sci. 2 (1990), pp. 227-234.

[2] Hammet Al, Young RL, Sun X, Chandra M. Non-wood fiber as an atrenative to wood fiber in China's pulp and paper industry. Holzforschung. 55 (2001), pp. 219-224.

[3] [Dephut] Departemen Kehutanan. Potensi Hutan Rakyat Indonesia [Internet]. (2004), Tersedia pada www.dephut.go.id.

[4] Husnain. Mengenal silika sebagai unsur hara. Warta Penelitian dan Pengembangan Pertanian. 32 (2010), pp. 19-20.

[5] Chindaprasirt P, Rukzon S, Sirivivatnanon. Resisitence to chloride penetration of blended Portland cement mortar containing palm oil fuel ash, rice husk ash and fly ash. Construction and Building Material. 22 (2008), pp. 932-938.

[6] Dwivedi VN, Singh NP, Dass SS, Singh NB. A new pozzolanicmaterial for cement industry: bamboo leaf ash. Int J Physics Sci. 1 (2006), pp. 106-111.

[7] Petrucci H Ralph. Kimia Dasar: Prinsip dan Terapan Modern. Jakarta, Erlangga (1987).

[8] Olugbenga O. Amu1, Akinwole A. Adetuberu. Characteristics of bamboo leaf ash stabilization on lateritic soil in highway construction. Int J Eng Tech. 2 (2010), pp. 212-219.

[9] Kurniati E. Ekstraksi Silica White Powder dari Limbah Padat Pembangkit Listrik Tenaga Panas Dieng. Surabaya, UPN Pr (2009).

[10] Turner FM. The Condensed Chemical Dictionary. 5th ed. New York, Reinhold Publish Corp (1956).

[11] Kirk O. Encylopedia of Chemical Technology. 3rd ed. Taiwan, J Wiley (1982), pp. 749-765.

[12] Irzaman, Darmasetiawan $\mathrm{H}$, Alatas $\mathrm{H}$, Irmansyah, Husin $\mathrm{AD}$, Indro $\mathrm{MN}$, Hardienata $\mathrm{H}$, Abdullah K, Mandang T, Tojo S. Optimization of thermal efficiency of cooking stove with rice hulk fuel in supporting the poliferation of alternative energy in Indonesia. Symposium Advanced Technological Depelopment of Biomass Utilization in Southeast Asia, Tokyo (2009), pp. 32-35.

[13] Aminullah, Rohaeti E, Irzaman. Reduction of high purity silicon from bamboo leaf as basic material in development of sensor manufacture in satellite technology, Procedia Enviromental Science. 24 (2015), pp. 308-316.

[14] Rohaeti E, Hikmawati, Irzaman. Production of semiconductor materials silicon from silica rice husk waste as alternative silicon. Materials Science and Technology. (2010), pp. 265-272.

[15] Ahmad L. Uji struktur dan sifat listrik silikon dioksida dan silikon dari sekam padi [tesis]. Bogor, Sekolah Pascasarjana, Institut Pertanian Bogor (2011).

[16] Masrur, Irmansyah, Irzaman. Optimasi kelajuan pemanasan pada ekstraksi ailikon diosida berbahan dasar sekam padi. Jurnal Biofisika. 9(2013), pp. 13-20.

[17] Verina H. Optimasi kelajuan auhu annealing untuk ekstraksi silika dari sbu sekam padi serta uji kandungan molekul [skripsi]. Bogor, Institut Pertanian Bogor (2014).

[18] Launer PJ. Infrared Analisys of Organosilicon Coumponds: Spectra-Structure Correlation. New York, Brunt Hill (1987).

[19] Silverstein RM, Bassler GC, Morril TC. Spectrometric Identification of Organic Compound. 5th ed. New York, J Willey (1991). 